\title{
Beckwith-Wiedemann syndrome in a child with chromosome 18q deletion
}

\author{
C M Brewer, W W K Lam, C Hayward, E Grace, E R Maher, D R FitzPatrick
}

Human Genetics Unit, Molecular Medicine Centre, Western General Hospital, Crewe Road, Edinburgh EH4 2XU, UK

C M Brewer

C Hayward

D R FitzPatrick

Division of Medical

Genetics, University of

Birmingham,

Birmingham B15 2TG,

UK

W W K Lam

E R Maher

Regional Cytogenetic Laboratory, RHSC, Edinburgh EH9 1TF, UK

E Grace

Correspondence to $\mathrm{Dr}$ Brewer.

Received 4 March 1997 Revised version accepted for publication 10 September 1997

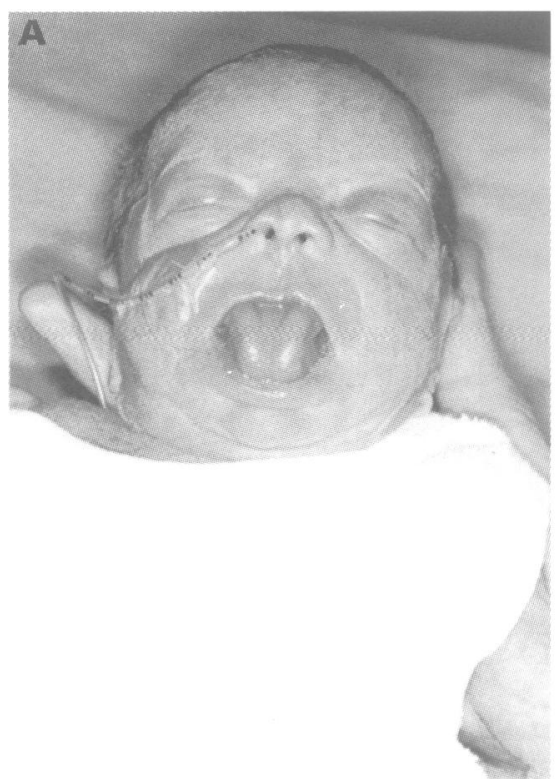

\begin{abstract}
Molecular genetic investigation of a female infant with Beckwith-Wiedemann syndrome (BWS) showed loss of IGF2 imprinting but no evidence of uniparental disomy. In addition, a deletion of chromosome 18q22.1 was identified in this infant without clinical features of 18q- syndrome (microcephaly, short stature, hypotonia). The association of a chromosome 18 deletion and BWS may be coincidental or may indicate the location of a trans activating regulator element for maintenance of IGF2 imprinting.

(F Med Genet 1998;35:162-164)
\end{abstract}

Keywords: chromosome deletion; chromosome 18q22.1; Beckwith-Wiedemann syndrome; imprinting

Deletion of the distal portion of chromosome $18 \mathrm{q}$ is a well recognised cytogenetic syndrome with well over 100 published cases. There is a phenotype common to many of the cases, characterised by microcephaly, midface hypoplasia, proximal thumbs, tapering fingers, hypotonia, short stature, and intellectual impairment. ${ }^{1-4}$ However, features are variable and clinical features do not always correlate with the size or location of the deleted portion. Atypical phenotypes have been reported with karyotypes apparently identical to those with the typical phenotype. ${ }^{25-8}$

Beckwith-Wiedemann syndrome (BWS) is a fetal overgrowth syndrome characterised by pre- and postnatal overgrowth, macroglossia, anterior abdominal wall defects, and ear lobe creases in the majority of cases and hypoglycaemia, hemihypertrophy, and an increased frequency of embryonal tumours in many. ${ }^{9}{ }^{10}$ The diagnosis is made clinically and guidelines put forward by Elliott and Maher ${ }^{11}$ require the presence of three major (abdominal wall defect, macroglossia, or overgrowth) or two major and three minor features. Chromosomes are usually normal in BWS although cytogenetic rearrangements involving chromosome 11 p 15 occur in $2-3 \%$ of cases. BWS usually occurs sporadically although around $15 \%$ of cases are familial. ${ }^{12}$

Linkage studies in the familial cases together with cytogenetic evidence have located the gene(s) responsible for BWS at chromosome $11 \mathrm{p} 15 .{ }^{13}$ Three genes (insulin-like growth factor 2 (IGF-2), $\mathrm{H} 19$, and $\mathrm{p} 57^{\mathrm{KIP} 2}$ ) have been implicated in the pathogenesis of BWS. All three genes map to $11 \mathrm{p} 15.5$ and are imprinted. IGF2 is a fetal growth promotor expressed from the paternal allele. ${ }^{14} \mathrm{H} 19$ and $\mathrm{p} 57^{\mathrm{KIP} 2}$ are suggested to have growth suppressor functions and are expressed from the maternal allele. Paternal uniparental disomy for chromosome 11 occurs in approximately $20 \%$ of cases of sporadic BWS. ${ }^{15} 16$ Biallelic IGF2 expression can be shown in the majority of non-disomic BWS cases. ${ }^{17}$ Recently, mutations in $\mathrm{p} 57^{\mathrm{KIP} 2}$ have been described in BWS. ${ }^{18}$

\section{Case report}

The female infant was born to healthy parents who already had two normal sons and had suf-

Figure 1 (A) Patient in infancy showing macroglossia and naevus flammeus over root of nose and left eyelid. (B) Patient at 14 months old showing macroglossia and generalised overgrowth. Hemihypertrophy of right hand is apparent. (C) Ear lobe crease.
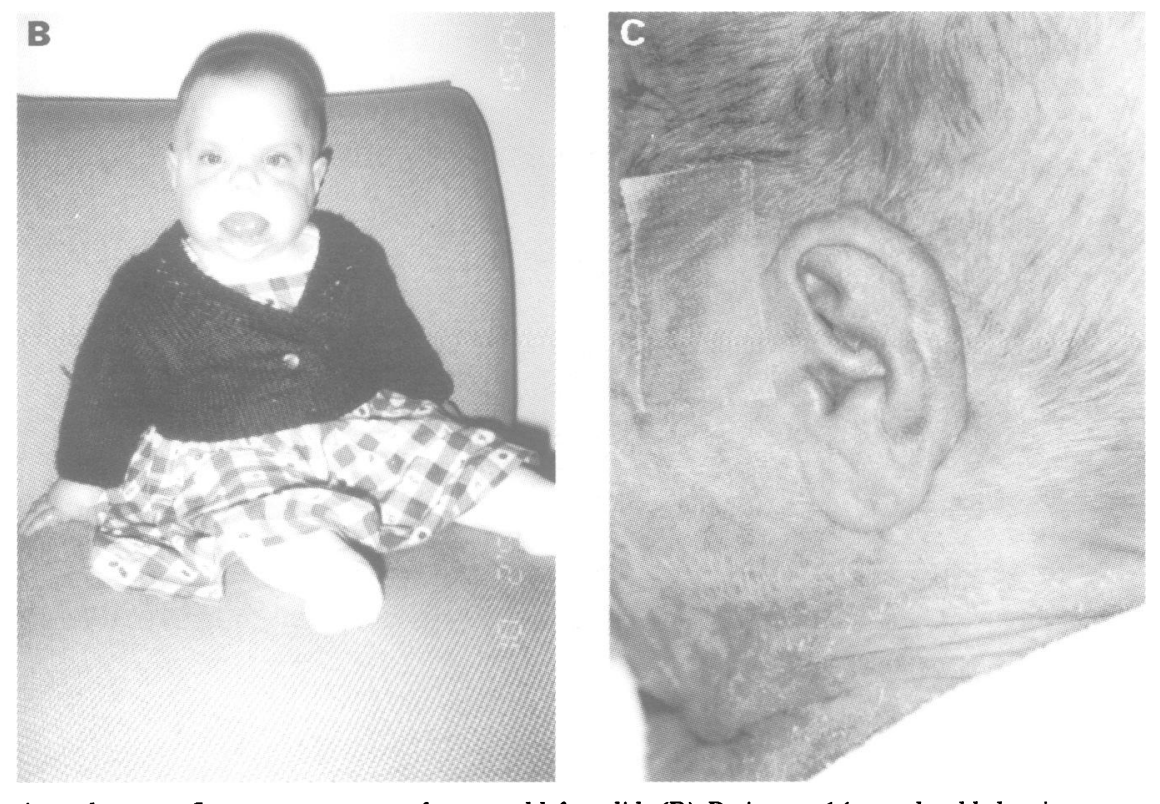
A

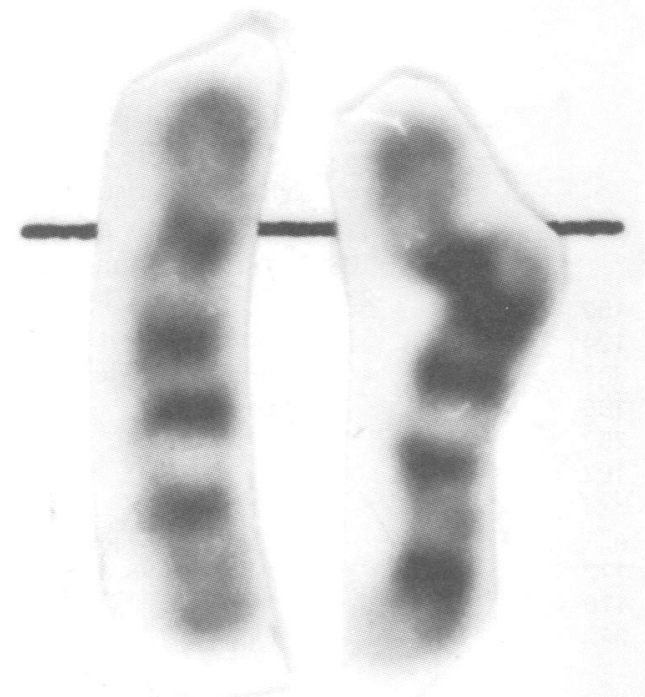

Figure 2 (A) Patient's chromosomes 18 with deletion at 18q22.1. (B) Chromosomes 18 from patient's father showing gap in band $q 22$.

fered three first trimester miscarriages. The father's sister had also had three early miscarriages but the family history was otherwise unremarkable. She was delivered at 32 weeks' gestation by emergency caesarean section for fetal distress in premature labour after a pregnancy complicated by polyhydramnios. Features of BWS were apparent at birth, notably a large, protruding tongue, transverse earlobe creases, facial capillary haemangioma, and a small umbilical hernia (fig $1 \mathrm{~A}, \mathrm{C}$ ). There was mild hypoglycaemia in the first 24 hours (glucose $1.3 \mathrm{mmol} / \mathrm{l}$ ), which resolved rapidly. Her birth weight was $2160 \mathrm{~g}$ (75th centile) and OFC $30.5 \mathrm{~cm}$ (50th centile).

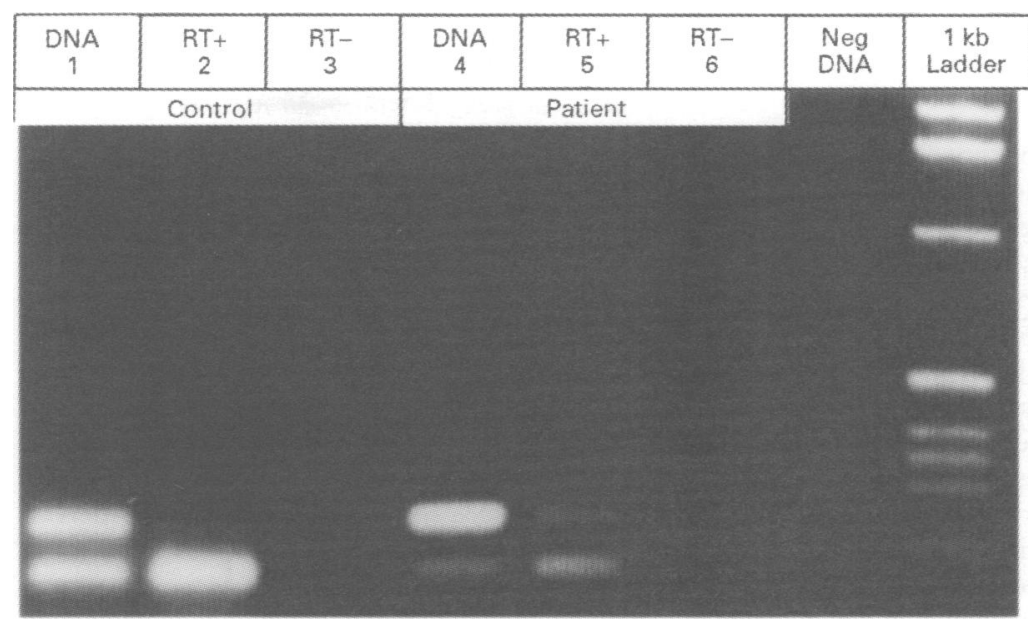

Figure 3 Analysis of IGF2 expression using exon 9 polymorphism. Lanes 1-3 are from a normal control. (1) Genomic DNA tract showing heterozygosity for ApaI polymorphism. (2) Normal monoallelic expression pattern of IGF2 using reverse transcriptase (RT) PCR. (3) Negative RT control to show absence of DNA contamination. Lanes 4, 5, and 6 are from BWS patient. (4) Genomic DNA tract showing heterozygosity for the ApaI polymorphism. (5) Clear biallelic expression pattern. (6) Negative RT control showing absence of DNA contamination. expression using the ApaI polymorphism as previously described. ${ }^{17}$ This showed clear evidence of IGF2 expression from both maternal and paternal alleles (fig 3).
B

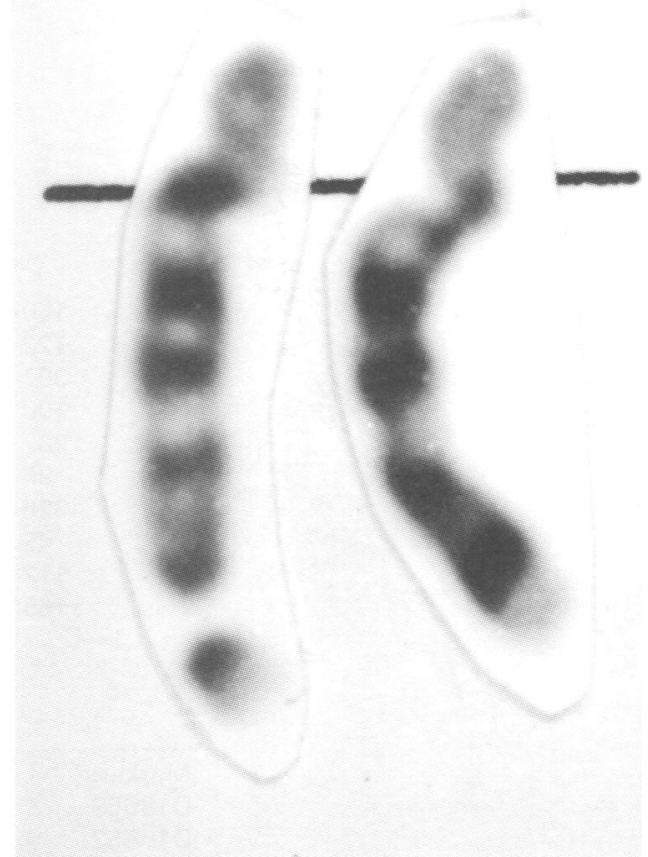

Early progress was slow, in part because of upper airways obstruction by her large tongue, and she required tube feeds until the age of 3 months and supplemental oxygen until 8 months. Transient hyperbilirubinaemia occurred during the first six weeks and phototherapy was given on two occasions. An abdominal ultrasound scan was normal and showed no signs of visceromegaly or renal malformation.

A diagnosis of BWS was likely on the basis of clinical findings, and although at birth her weight was not above the 90th centile, she has displayed postnatal overgrowth, thereby satisfying the diagnostic criteria. ${ }^{11}$

Chromosome analysis produced the unexpected finding of a chromosome deletion, 46,XX,del(18)(q22.1) (fig 2A). Parental chromosomes were normal apart from an apparent fragile site at $18 \mathrm{q} 22.1$ in $2 / 60$ and $1 / 140$ cells in two separate lymphocyte cultures from her father (fig 2B).

\section{MOLECULAR GENETIC ANALYSIS} ried out using microsatellite markers at the $\mathrm{TH}$ locus as described previously, ${ }^{16}$ but this was uninformative. To investigate further for UPD, the $\mathrm{H} 19$ methylation index was estimated as described by Reik et $a l^{19}$ and Catchpoole $e t a l^{20}$ and was within normal limits, thus making UPD unlikely. We proceeded to look at IGF2 


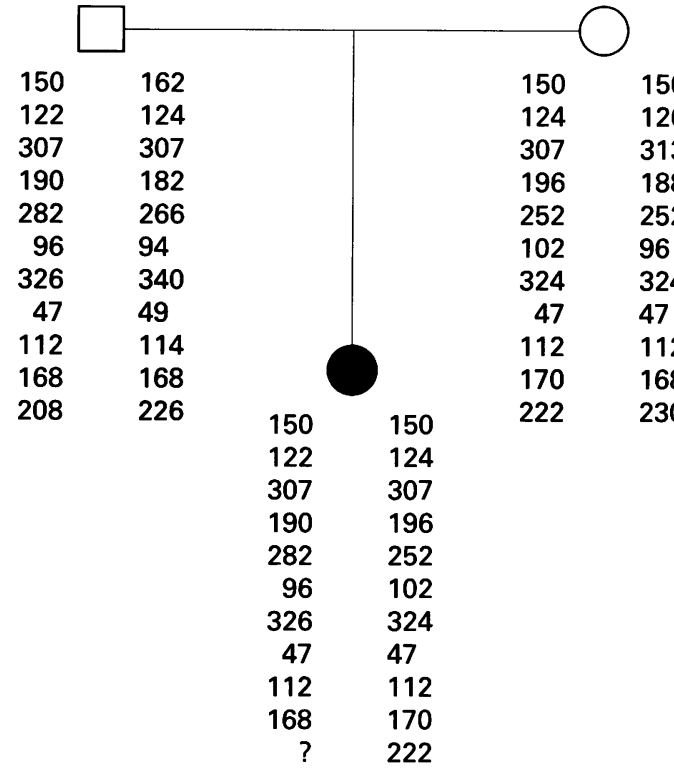

\begin{tabular}{|ll|}
\hline Markers & Alleles \\
D18S59 & 150,162 \\
D18S52 & $122,124,126$ \\
D18S62 & 307,313 \\
D18S53 & $182,188,190,196$ \\
D18S71 & $252,266,282$ \\
D18S57 & $94,96,102$ \\
D18S64 & $324,326,340$ \\
D18S60 & 47,49 \\
D18S55 & 112,114 \\
D18S477 & 168,170 \\
D18S61 & $208,222,226,230$ \\
\hline
\end{tabular}

Figure 4 CA repeat markers showing a paternally derived deletion in the proband.

CHROMOSOME 18 DELETION MAPPING

The cytogenetic deletion was confirmed molecularly using PCR based polymorphic markers and this narrowed the deletion breakpoint to a $1 \mathrm{Mb}$ region between markers D18S477 and D18S61 (fig 4). The deletion is clearly of paternal origin but it is not possible to determine whether this is derived from the father's chromosome with the fragile site or from its homologue.

\section{Discussion}

This case is noteworthy because of the association of a convincing clinical diagnosis of BWS and bialleleic IGF2 expression with a cytogenetic deletion of chromosome 18 . While these two findings could be unrelated, an interesting possibility is that the chromosome 18 deletion has resulted in deletion of a trans acting regulator of IGF2 imprinting. Although IGF2 and chromosome $11 \mathrm{p} 15$ genes have been clearly implicated in the pathogenesis of BWS, in one family linkage to IGF2 was excluded. ${ }^{21}$ In addition, there is experimental evidence to suggest the involvement of trans acting factors in normal genomic imprinting. ${ }^{19}{ }^{21}$ However, there are no other reports of chromosome 18 abnormalities in BWS although a chromosome 16 rearrangement has been described previously. The location of the chromosome 18 breakpoint may reflect the observation of a previously undescribed fragile site in the father of our case, analogous to the association of a (CGG)n repeat at a rare autosomal folate sensitive fragile site ( $11 \mathrm{p})$ in the parent of a child with Jacobson syndrome. ${ }^{22}$ A site specific effect, such as the deletion of a downstream transcriptional repressor element, may explain why other deletions involving this chromosome region do not result in BWS. Investigations to identify the deletion breakpoint are currently in progress.

1 de Grouchy J, Royer P, Salmon C, Lamy M. Deletion parteille des bras longs du chromosome 18. Pathol Biol parteille des bras

2 Wilson MG, Towner JW, Forsman I, Siris E. Syndrome associated with deletion of the long arm of chromosome 18 (del 18q). Am F Med Genet 1979;3:155-74.

3 Felding I, Kristoffersson U, Sjostrom H, Noren O Contribution to the $18 \mathrm{q}-$ syndrome. A patient with $\operatorname{del}(18)$ (q22.3qter). Clin Genet 1987;31:206-10

4 Miller G, Mowrey PN, Hopper KD, Frankel CA, Ladda RI Neurological manifestations in 18q- syndrome. $\mathrm{Am} \mathcal{F} \mathrm{Med}$ Genet 1990;37:128-32.

5 Strathdee G, Zackai EH, Shapiro R, Kamholz J, Overhauser $\mathrm{J}$. Analysis of clinical variation seen in patients with $18 \mathrm{q}$ terminal deletions. Am $\mathcal{F}$ Med Genet 1995;59:476-83.

6 Qazi QH, Madahar C, Alvi S, McGann B. Distal 18q deletion without findings of $18 \mathrm{q}-$ syndrome. Ann Genet tion without

7 Kline $\mathrm{AD}$, White ME, Wapner $\mathrm{R}$, et al. Molecular analysis of the $18 \mathrm{q}$ - syndrome and correlation with phenotype. $A m \mathcal{F}$ the 18q- syndrome and corr

8 Kohonen-Corish M, Strathdee G, Overhauser J, McDonald $\mathrm{T}$, Jammu V. A new deletion of 18q23 with few typical features of the 18q- syndrome. F Med Genet 1996;33:240-3.

9 Beckwith JB. Extreme cytomegaly of the adrenal feta cortex, omphalocoele, hyperplasia of the kidneys and pan creas and Leydig cell hyperplasia - another syndrome? Presented at the Annual Meeting of Western Society for Pediatric Research, Los Angeles, California, 21 November 1963.

10 Wiedemann HR. Complexe malformatif familial avec hernie ombilicale et macroglossie - un "syndrome nouveau?" $f$ Genet Hum 1964;13:232-3.

11 Elliott M, Maher ER. Beckwith-Wiedemann syndrome. $f$ Med Genet 1994;31:560-4.

12 Viljoen D, Ramesar R. Evidence for parental imprinting in familial Beckwith-Wiedemann syndrome. $\mathcal{F}$ Med Genet 1992;29:221-5.

13 Ping AJ, Reeve AE, Law DJ, Young MR, Boehnke M, Fein berg AP. Genetic linkage of Beckwith-Wiedemann syndrome to 11 p15. Am F Hum Genet 1989;44:720-3.

14 Schneid H, Seurin D, Vazquez MP, Gourmelen M, Cabro $S$, Le Bouc Y. Parental allele specific methylation of the human insulin-like growth factor II gene and BeckwithWiedemann syndrome. $\mathcal{F}$ Med Genet 1993;30:353-62.

15 Henry I, Bonaiti-Pellie C, Chehensse V, et al. Uniparenta paternal disomy in a cancer-predisposing syndrome. Nature 1991;351:665-7.

16 Slatter RE, Elliott $M$, Welham $K$, et al. Mosaic uniparental disomy in Beckwith-Wiedemann syndrome. 7 Med Genet 1994;31:749-53.

17 Joyce J, Lam WWK, Catchpoole D, Maher ER, Schofield PN. Lack of reciprocity of imprinting of $\mathrm{H} 19$ and IGF2. Hum Mol Genet (in press)

18 Hatada I, Ohashi $H$, Fukushima $Y$, et al. An imprinted gen $\mathrm{p} 57^{\mathrm{KIP} 2}$ is mutated in Beckwith-Wiedemann syndrome. Na Genet 1996,14:171-3.

19 Reik W, Brown KW, Slatter RE, Sartori P, Elliott M, Maher ER. Alleleic methylation of $\mathrm{H} 19$ and IGF2 in the Beckwith-Wiedemann syndrome. Hum Mol Genet 1994;3 1297-301.

20 Catchpoole D, Lam WWK, Valler D, et al. Epigenetic modification and uniparental inheritance of H19 in BeckwithWiedemann syndrome. $\mathcal{F}$ Med Genet 1997;34:353-9.

21 Reik W, Feil R, Nicholas D, Moore N, Walter J. Imprinted genes, alleleic methylation and imprinted modifiers of methylation. In: Genomic imprinting: courses and consequences. Cambridge: Cambridge University Press, 1995: 157-69.

22 Jones C, Slijepcevic P, Marsh S, et al. Physical linkage of the fragile site FRA1 1 B and a Jacobsen syndrome chromosome deletion breakpoint in 11q23.3. Hum Mol Genet 1994;3: 2123-30. 